\title{
Mais Participação, Maior Responsividade? As Conferências Nacionais de Políticas Públicas e a Qualidade da Democracia no Brasil
}

\author{
Thamy Pogrebinschi ${ }^{1}$ \\ Tiago Ventura ${ }^{2}$ \\ 1. Universidade Humboldt de Berlim (BGSS/HU), Berlim, Alemanha. E-mail: \\ thamy.pogrebinschi@wzb.eu. \\ 2. University of Maryland (College Park), Maryland, Estados Unidos.
}

\begin{abstract}
A defesa das chamadas "inovações democráticas" (Smith, 2009) ou A "instituições participativas" (Avritzer, 2009) enquanto antídotos para o aumento da insatisfação política e da desconfiança nas instituições representativas não consiste mais em novidade. Nos últimos anos, multiplicaram-se os estudos que identificam em tais mecanismos capacidade para ampliar o papel dos cidadãos no processo de tomada de decisões (Avritzer, 2002; Smith, 2009), solucionar os dilemas da representação (Seele e Peruzzotti, 2009; Geissel e Newton, 2012) e, assim, aprofundar a democracia (Fung e Wright, 2003) ou aumentar sua qualidade (Geissel, 2009; Geissel e Joas, 2013). No entanto, entre "aprofundar a democracia" e "aumentar a qualidade democrática" há uma distância conceitual e empírica ainda a ser percorrida, especialmente quando se quer vindicar uma ou outra como solução para a chamada "crise da representação" (Köchler, 1987; Hayward, 1996; Alonso, Keane e Merkel, 2011) ou "crise da democracia" (Crozier, Huntington e Watanuki, 1975; Habermas, 1975; Linz e Stepan, 1978; Morlino, 1998; Kaase e Newton, 2005; Merkel, 2014).
\end{abstract}

A questão do aprofundamento democrático é um dos principais temas da agenda da teoria da democracia contemporânea. Acompanhando uma diversificada e profícua discussão conceitual sobre participação e deliberação, estudos de caso sobre inovações específicas abundam na literatura, buscando mostrar como aquelas, conferindo protagonismo ao cidadão e desenvolvendo suas capacidades, revigoram a DADOS - Revista de Ciências Sociais, Rio de Janeiro, vol. 60, n-1 1, 2017, pp. 7 a 43. 
democracia. Tais estudos comumente se apoiam em abordagens da democracia participativa (Barber, 2004; Pateman, 1970; Mansbridge, 1983; Warren, 2002), da democracia deliberativa (Habermas, 1989; Bohman, 1998, Gutmann, 2004; Dryzek, 2000; Fishkin, 1991), de uma concepção mais abrangente e plural da representação política (Urbinati, 2006; Gurza Lavalle, Houtzager e Castello, 2006; Castiglione e Warren, 2006), e da governança participativa "empoderada" (Fung e Wright, 2003). Tais reflexões formam a base teórica dos estudos sobre inovações participativas, partindo da crítica às concepções minimalistas e apontando novos mecanismos participativos e deliberativos como capazes de aprofundar as democracias.

De outro lado, o problema da qualidade da democracia ocupa crescente espaço no campo dos estudos de política comparada. Com as transições democráticas completadas em praticamente todo o mundo, o tema da consolidação da democracia cede lugar à preocupação com a sua qualidade. Há um esforço sistemático para aperfeiçoar índices e medidas, de modo a avaliar a qualidade democrática ao redor do globo.

O diálogo entre as duas áreas de conhecimento é, contudo, praticamente inexistente. A teoria democrática contemporânea clama que, ao aprofundar-se a democracia por meio de mecanismos de participação e deliberação, vê-se aumentada a sua qualidade. No entanto, esse argumento padece, rigorosamente, de três dificuldades. A primeira é que ele se baseia em estudos de casos de inovações democráticas específicas, sendo ainda minoritárias as análises comparativas e mais sistemáticas. A segunda é que tais estudos de caso quase sempre focam no nível local, sendo menos frequentes os estudos que têm por objeto instituições participativas nacionais ou que buscam aferir o impacto de inovações institucionais no âmbito nacional (entre estes últimos, encontram-se Avritzer, 2010; Avritzer e Souza, 2013; Donaghy, 2011; Pogrebinschi e Santos, 2011; Pogrebinschi e Samuels, 2014; Wampler e Touchton, 2013). Por fim, a terceira dificuldade é que, ao fazer tal argumento, a teoria democrática não recorre ao conceito de qualidade da democracia que serve de base a diversos índices (como, por exemplo, Freedom House, Democracy Barometer, Economist Intelligence Unit Democracy Index, Polyarchy/Vanhanen etc.) e pesquisas de opinião pública (como, por exemplo, Eurobarômetro, Latinobarômetro, World Values Survey etc.), assim como às auditorias e estudos que buscam mensurar e comparar a democracia nos diversos países do mundo 
(como, por exemplo, Diamond e Morlino, 2005; Levine e Molina, 2011; O’Donnell, Vargas Cullell e Iazzetta, 2004).

Por sua vez, tais índices, pesquisas de opinião e estudos apoiam-se em um conceito minimalista de democracia e em uma noção ultrapassada de participação, invariavelmente medindo esta última apenas com base no comparecimento às urnas e no exercício de direitos políticos. Nos últimos anos, algumas pesquisas de opinião pública passaram a estender o conceito de participação a critérios como engajamento em protestos, assinatura de petições e frequência em associações de moradores ou outras entidades. Esse foi um passo não desprezível no sentido de considerar a participação para além do direito de sufrágio e do exercício do voto, embora todas aquelas práticas configurem meramente o exercício de direitos políticos básicos, de associação e livre expressão do pensamento, e não exatamente inovações institucionais cujo fito seja incrementar a participação dos cidadãos ou alargar a democracia.

Os diversos experimentos participativos e deliberativos que proliferaram nos últimos anos ao redor do mundo e que, em muitos desses lugares, vêm se institucionalizando de forma crescente ainda são ignorados enquanto componentes da variável participação, assim como seus eventuais impactos nas outras dimensões pelas quais se pode avaliar a qualidade da democracia como, por exemplo, competição política, responsividade, accountability etc. Isso se reflete nos estudos de política comparada que tomam aqueles índices e pesquisas como base para mensurar a democracia, tendo em vista que ainda lançam mão de definições minimalistas de participação e representação (Altman e PérezLiñán, 2002; Levine e Molina, 2011; Diamond e Morlino, 2005) e ignoram o esforço recente da teoria democrática para atualizar esses conceitos (Castiglione e Warren, 2006; Urbinati, 2006; Urbinati e Warren, 2008; Saward, 2009).

A falta de diálogo entre a literatura de teoria democrática e a de política comparada é tão problemática quanto o descompasso entre os conceitos de participação e as avaliações concretas que buscam mensurar a democracia. Sem atentar para os índices e medições existentes, estudos de casos de inovações participativas dificilmente podem ser bemsucedidos em afirmar que estas aumentam, de fato, a qualidade da democracia, devendo, assim, limitar-se ao argumento um tanto abstrato de que promovem seu "aprofundamento". Por outro lado, sem incor- 
porar um conceito mais abrangente e atual de participação, tais índices e avaliações produzirão mensurações incompletas, deixando de lado expressões cada vez mais relevantes da vida democrática.

Na América Latina, onde experimentos participativos são cada vez mais frequentes e encontram um grau cada vez maior de institucionalização, tal problemática é ainda mais preocupante. No Brasil, por exemplo, milhares de pessoas têm se engajado nas diversas instituições participativas existentes tanto no nível local como no nacional. Os efeitos da inclusão de cidadãos e organizações da sociedade civil no ciclo de políticas públicas são cada vez mais perceptíveis, seja pelo seu potencial redistributivo (Sousa Santos, 1998; Baiocchi, 2003; Wampler, 2007; Avritzer, 2009), ou pelo seu potencial de influenciar a formulação de políticas (Pogrebinschi e Santos, 2011; Pogrebinschi e Samuels, 2014) e sua implementação (Tatagiba, 2005; Lüchmann, 2007; Donaghy, 2011). Quando mecanismos participativos passam a exercer algum tipo de efeito no processo político-decisório e no bem-estar da sociedade, eles não podem deixar de ser considerados nas mensurações da qualidade da democracia. De forma análoga, quando experimentos participativos e deliberativos são, seja em seus pressupostos ou em seus efeitos, vinculados ao desenho das instituições representativas, sua presença não pode ser desprezada nas definições de participação política que embasam tais mensurações. Isso parece ter sido percebido recentemente por Gabriel Katz e Leonardo Morlino (2013), os primeiros a levarem em consideração a presença de experiências participativas e deliberativas em uma avaliação da qualidade da democracia a qual, não surpreendentemente, teve como foco a América Latina.

É razoável supor que inovações democráticas de caráter participativo ou deliberativo tenham capacidade de alavancar a qualidade da democracia, especialmente quando são de algum modo conectadas às instituições representativas. Mas, para tanto, é preciso superar divisões disciplinares e fazer avançar um conceito mais abrangente de participação, investigando empiricamente como esta pode impactar outras dimensões essenciais à mensuração da qualidade das democracias contemporâneas. Tal posição foi defendida e estruturada teoricamente em trabalho recente (Pogrebinschi, 2013). O argumento central é que experimentos participativos e deliberativos têm o potencial de ativar a competição política, a responsividade e a igualdade - dimensões essenciais a qualquer avaliação da qualidade da democracia. Neste 
artigo, pretende-se explorar empiricamente tal construção teórica no que se refere à dimensão da responsividade.

Para tanto, nas próximas páginas buscaremos aferir se as Conferências Nacionais de Políticas Públicas (CNPPs) despertaram ou não uma maior responsividade do Poder Legislativo brasileiro. Isso será feito em três passos. Primeiro, apresentaremos um modelo de análise da responsividade, complementando o modelo teórico proposto no trabalho anterior. Em seguida, explicaremos o desenho da pesquisa empírica e analisaremos seus resultados vis-à-vis o modelo teórico proposto. Constatando a responsividade do Poder Legislativo, concluiremos apontando o potencial de mecanismos participativos e deliberativos para aumentar a qualidade da democracia.

As CNPPs são espaços de participação e deliberação da sociedade sobre políticas públicas. São convocadas pelo Poder Executivo, frequentemente em parceria com a sociedade civil, possibilitando que ambos os lados juntos discutam e construam diretrizes, isto é, recomendações de políticas a serem possivelmente adotadas pelo governo em determinadas áreas. As CNPPs são organizadas em torno de temas ou áreas de políticas e seguem um processo escalonado que tem início nos municípios, segue para os estados federados por meio da eleição de delegados e da aprovação de diretrizes e, em seguida, é concluído com uma etapa nacional. As CNPPs têm demonstrado ao longo dos anos enorme capacidade de mobilização, agregando, sobretudo, atores coletivos, como ONGs e movimentos sociais, ao lado de cidadãos comuns e representantes estatais dos três níveis da federação. As diretrizes, ou recomendações de políticas, que resultam desse intenso processo coletivo de participação e deliberação não possuem caráter vinculante isto é, o governo não está obrigado a cumpri-las - porém são claras indicações das preferências que a sociedade gostaria de ver respondidas pelas instituições representativas ${ }^{1}$.

Nossos resultados pretendem contribuir para o debate sobre a efetividade das inovações democráticas, propondo um desenho de pesquisa novo para este fértil campo de estudos e apresentando novos argumentos às investigações que têm chamado atenção para sinais de esgotamento dessas experiências e para a dificuldade de converter deliberações em políticas (Almeida e Tatagiba, 2012; Pires, 2011; Souza, 2013). 


\section{RESPONSIVIDADE E QUALIDADE DA DEMOCRACIA: UM NOVO MODELO DE ANÁLISE}

O debate em torno do conceito de qualidade da democracia e das medidas mais apropriadas para avaliá-la tem rendido uma crescente literatura no campo da política comparada. Iniciando-se com a obra seminal de Arend Lijphart (1999), mas apoiando-se ainda imensamente no conceito de poliarquia de Robert Dahl (1971), estudos de natureza teórica e empírica somam-se na tentativa de oferecer um conceito abrangente de democracia que permita superar as limitações de sua definição minimalista ao destacar suas diversas dimensões (O'Donnell, Vargas Cullell e Iazzetta, 2004; Lauth, 2004; Levine e Molina, 2011; Diamond e Morlino, 2005), atributos (Munck e Verkuilen, 2002) ou qualidades (Morlino, 2011) a partir das quais a (qualidade da) democracia deve ser compreendida e avaliada.

Com bastante variação, apesar de pouca divergência, a literatura tende a classificar os vários atributos conceituais da democracia com base em sua incidência no processo democrático ou em seus resultados (Munck, 2016). Morlino (2011) oferece talvez uma das conceitualizações mais completas, propondo que a qualidade da democracia seja compreendida em termos de procedimento, conteúdo e resultado, os quais se desdobram em oito dimensões. Considerar a qualidade da democracia em termos de procedimento implica tomar como critério de análise as dimensões estado de direito (rule of law), accountability (eleitoral e interinstitucional), competição e participação. Já a qualidade em termos de conteúdo implica considerar as dimensões da liberdade e da igualdade. Por fim, o foco nos resultados determina a oitava das dimensões, qual seja a responsividade.

Este artigo parte da percepção acerca da necessidade de definir-se uma nova teorização causal que explique a qualidade da democracia por meio de fatores não considerados na literatura sobre democratização (Mazzuca, 2010). Também concordamos com a importância de se reconceitualizar a democracia a fim de superar sua definição minimalista e encontrar meios de mensuração que possam ir além da ideia de democracia eleitoral ou representativa (Munck, 2016). Mas, para além disso, este artigo parte também do pressuposto de que uma das dimensões substantivas do conceito de qualidade da democracia, a participação, quando atualizada e expandida de forma a abarcar inovações democráticas participativas e deliberativas, pode fortalecer outras de 
suas dimensões, como, por exemplo, a competição, a igualdade e a responsividade (Pogrebinschi, 2013).

No que tange à responsividade, objeto específico deste artigo, proporemos um modelo analítico que, em certa medida, expande o campo semântico de aplicação do conceito a fim de coaduná-lo com uma perspectiva não minimalista de democracia que extrapole a dimensão eleitoral e, com isso, expanda a própria noção de representação. Partindo de Powell (2004), que define responsividade como a "habilidade da democracia de transformar as preferências dos cidadãos em políticas", assumimos que tal processo de transformação pode ser fortalecido pela adoção de mecanismos participativos e deliberativos. Se a responsividade depende da "emissão prévia de mensagens dos cidadãos" (Manin, Przeworski e Stokes, 1999:9) e um governo ou instituição é considerado responsivo "se adota políticas que são sinalizadas pelos cidadãos como suas preferidas" (idem), é razoável supor que a ampliação dos canais através dos quais os cidadãos possam emitir tais mensagens implicará um aumento da responsividade.

No contexto da democracia representativa, cidadãos sinalizam suas políticas preferidas primordialmente por meio das eleições. Ao votar em determinados candidatos, os cidadãos sinalizam que a plataforma dos partidos políticos aos quais aqueles pertencem aproximam-se de suas preferências individuais, assumindo que do programa partidário e da coesão e disciplina de seus representantes eleitos resultarão políticas que lhes sejam satisfatórias. De forma análoga, ao deixar de votar em certos candidatos e partidos, os cidadãos sinalizam que políticas não foram formuladas com base em suas preferências de forma satisfatória, de modo que governos e parlamentos não teriam, nesse caso, agido de forma responsiva.

Há vários problemas com o modelo de responsividade ancorado no voto. Primeiro, ao centrar-se exclusivamente nas eleições, fica-se sujeito aos problemas de escolha coletiva inerentes aos métodos agregativos. Não é nenhuma novidade que diferentes sistemas de votação implicam diferentes resultados e que a vontade da maioria pode ser facilmente deturpada por regras e procedimentos eleitorais: uma extensa literatura lidou com esses problemas derivados da aplicação do Teorema da Impossibilidade de Arrow e do Paradoxo de Condorcet (Riker, 1980; Scharpf, 1970; Schmidt, 1995). Segundo, tomar o voto como método primordial de transformação de preferências implica 
não apenas desconfigurar eventualmente a vontade da maioria, como também em ignorar a vontade das minorias. Estas, quando não conseguem eleger seus representantes, ficam privadas de representação. A eleição enquanto princípio de alternância no poder não oferece nenhuma garantia de que grupos minoritários possam, eventualmente, vir a ser representados se não lograrem converter-se em maiorias. Terceiro, funcionalidades e desfuncionalidades dos sistemas eleitorais impedem que a representação seja efetivamente ancorada numa relação entre principal e agente, não obstante a natureza da delegação conferida. Em sistemas proporcionais de lista aberta, representantes eleitos não têm como saber quem são seus eleitores, assim como os cidadãos não têm conhecimento sobre os parlamentares que efetivamente ajudaram a eleger. Não há autorização possível, nem mesmo para que se estabeleça uma representação meramente virtual de estilo burkiano. Além disso, a crescente volatilidade eleitoral, critério tão usado para medir a estabilidade das instituições representativas, é certamente um expressivo sinal de que as preferências dos cidadãos tendem a ser mais dinâmicas que o procedimento eleitoral.

Os problemas acima indicam a necessidade de que sejam identificados novos meios por meio dos quais os cidadãos possam, conforme prescrevera Dahl, "formular suas preferências, significá-las para seus concidadãos e para o governo por meio de ação individual e coletiva, e tê-las consideradas igualmente na conduta deste último sem discriminação com base no conteúdo ou fonte das preferências" (Dahl, 1971:2). Os mecanismos participativos e deliberativos certamente constituem um desses meios, e seu potencial para aumentar a responsividade de governos e parlamentos é uma das principais razões pelas quais, ao contrário do que alguns (ainda) pensam, a ampliação da participação vem a fortalecer a representação, sem estabelecer com ela nenhum tipo de antagonismo. Novas formas de participação podem minimizar distorções às quais o voto está, devido a sua própria natureza, sujeito.

As chamadas inovações democráticas oferecem aos cidadãos mais chances de formular e significar as suas preferências, assim como oferece aos representantes eleitos mais oportunidades para receber os sinais emanados pelos cidadãos a respeito das políticas que lhes são preferidas. Adicionando-se mais participação, a velha "conexão eleitoral" (Mayhew, 1974) apenas pode vir a se reforçar: preferências sinalizadas por atuais não eleitores podem vir a ser respondidas por representantes em busca de novos eleitores futuros. Representantes podem restau- 
rar vínculos com eleitores antigos e partidos passam a dispor de novos espaços para mobilizar suas bases e angariar novos membros. Operando no período entre eleições, mecanismos participativos atuam como "third-party speakers" (Lupia e McCubbins, 1998), suprindo os representantes com mais informações sobre seus atuais e potenciais eleitores, contribuindo, assim, para resolver problemas de delegação e restaurar a relação principal-agente que configura a representação. Por fim, as inovações democráticas permitem que os cidadãos expressem suas preferências num continuum mais largo que aquele usualmente oferecido por plataformas partidárias, assim como permitem que representantes atuem num continuum mais amplo que aquele inicialmente assumido como direita-esquerda ou governo-oposição. As chances de governos e parlamentos agirem de forma responsiva, formulando políticas mais próximas das preferências dos cidadãos, apenas tendem, em tese, a aumentar.

Tradicionalmente, a responsividade é mensurada com base em medidas atitudinais de satisfação dos cidadãos com a democracia e de sua confiança nas instituições representativas, tais como as oferecidas pelos diversos surveys existentes. A literatura especializada propõe adicionalmente mecanismos de medição da distância entre representantes e representados em face de certas políticas (e.g. Lijphart, 1999:286-288; Eulau e Karps, 1977; Huber e Powell, 1994). Ao somar mecanismos não eleitorais ao conceito de participação, pode-se, contudo, potencialmente superar os limites normativos do conceito de responsividade que levaram Hans-Joachim Lauth (2004) a afirmar que este deve apenas circunstancialmente ser tomado como expressão da qualidade da democracia. Um modelo que leva em conta a sensibilidade de governos e instituições aos novos mecanismos participativos certamente faculta uma mensuração mais efetiva da responsividade enquanto dimensão essencial da qualidade democrática. O modelo analítico proposto e testado nas próximas páginas busca contribuir neste sentido.

\section{OS TRÊS NÍVEIS DA RESPONSIVIDADE}

A fim de reconceitualizar responsividade vis-à-vis os novos mecanismos participativos, recorreremos ao método de construção de "conceitos de três níveis" de Gary Goertz (2006). O autor propõe uma abordagem ontológica e causal para a construção de conceitos, desdobrando-os em três níveis: o conceito central, o nível secundário e 
os indicadores. O primeiro consiste no elemento teórico a ser explicado; o segundo nível refere-se às atribuições qualificadoras do conceito - o que, com base em tal metodologia ontológica, não se trata de um elenco normativo de definições do que se pretende explicar, mas, sim, a identificação, com base na realidade social, dos elementos que constituem o conceito em questão. Por fim, o terceiro nível refere-se aos indicadores e dados que possibilitam a comprovação empírica do nível anterior do conceito.

A adoção de tal método justifica-se pela sua ênfase na causalidade inerente à reconstrução conceitual. A perspectiva ontológica de Goertz traz consigo elementos importantes na definição da causalidade do fenômeno a ser explicado. Ao evitar uma postura normativa na definição do conceito em questão, busca-se identificar os fenômenos que constituem o nível secundário do conceito em seu contexto fático. Por exemplo, no caso da democracia como conceito principal, responsividade figuraria, entre outros, no nível secundário da maior parte das definições. Enquanto nível secundário do conceito de democracia, a responsividade tem usualmente como um de seus indicadores, conforme mencionamos acima, a satisfação dos cidadãos com a democracia e sua confiança nas instituições políticas. Este exemplo permite perceber como, na metodologia proposta por Goertz, os elementos constitutivos do conceito estabelecem de forma lógica uma relação causal com o próprio: se determinada característica aparece ontologicamente no conceito, isso significa que há contornos causais na sua existência e na do elemento abstrato em questão. Assim, responsividade causa o que se define como democracia, enquanto satisfação com a democracia e confiança nas instituições políticas causam responsividade. A metodologia de Goertz é extremamente útil para o desenvolvimento de modelos teóricos com base em pesquisas empíricas, e vice-versa.

A abordagem ontológica proposta em Goertz, apesar de nos permitir uma reconstrução causal do conceito de responsividade, limita a utilização do conceito aqui proposto. Em se tratando de um processo de identificação fática para construção dos níveis do conceito, deve-se considerar em sua elaboração as próprias características do objetivo de análise: as Conferências Nacionais de Políticas Públicas. Em decorrência da diversidade de desenhos institucionais de inovações participativas ou deliberativas no Brasil, ao considerar o objeto de estudo na elaboração conceitual, termina-se por limitar a estratégia de utilização do conceito ao objeto em tela. Assim, a adoção do conceito proposto de 
responsividade na análise de outras inovações exige uma nova reconstrução conceitual, em especial, sobre suas características secundárias e seus indicadores.

O modelo de análise que propomos desdobra o conceito de responsividade em três níveis intermediários: impacto nas políticas públicas, congruência temática, e multidimensionalidade da representação política. O primeiro refere-se à capacidade do governo e do Legislativo de converter em políticas públicas as preferências expressas pelos cidadãos e atores sociais coletivos por meio de mecanismos participativos. O segundo consiste na existência de congruência substantiva entre as preferências expressas nas novas instâncias participativas e a ação das instituições representativas. Por fim, o terceiro nível consiste no potencial multidimensional da representação estimulada pelos mecanismos participativos. Cada um dos níveis secundários será construído com base em alguns indicadores, descritos no Quadro 1.

\section{Quadro 1}

Os Três Níveis do Conceito de Responsividade

\begin{tabular}{|l|c|l|}
\hline Conceito & Nível Secundário & \multicolumn{1}{|c|}{ Indicadores } \\
\hline \multirow{1}{*}{ Responsividade } & $\begin{array}{c}\text { Impacto nas Políticas } \\
\text { Públicas }\end{array}$ & $\begin{array}{l}\text { Formulação de Políticas Públicas com } \\
\text { base nas preferências expressas nas } \\
\text { instâncias participativas }\end{array}$ \\
\cline { 2 - 3 } & $\begin{array}{l}\text { Congruência Temática } \\
\text { Correspondência substantiva entre as } \\
\text { preferências expressas nas instâncias } \\
\text { participativas e as iniciativas legislativas e } \\
\text { leis propostas no parlamento ou } \\
\text { emanadas pelo governo }\end{array}$ \\
\cline { 2 - 3 } & $\begin{array}{l}\text { Multidimensionalidade } \\
\text { da Representação }\end{array}$ & $\begin{array}{l}\text { Respostas das diferentes clivagens } \\
\text { partidárias do parlamento } \\
\text { (esquerda-direita, governo-oposição) e } \\
\text { dos poderes estatais } \\
\text { (Legislativo-Executivo) às preferências } \\
\text { expressas nos espaços participativos }\end{array}$ \\
\hline
\end{tabular}

Fonte: Elaboração dos autores.

No que tange ao primeiro dos níveis intermediários, o impacto nas políticas públicas, servirão como indicadores as respostas positivas dos legisladores às deliberações finais das CNPPs. Todas as conferências nacionais incluídas nesta pesquisa tiveram como resultado a produção de um documento final destinado ao conhecimento dos poderes públicos. Do documento, foram retiradas aquilo que neste artigo chamamos 
de diretrizes, ou seja, recomendações ou propostas de políticas públicas. Essas diretrizes podem ter natureza executiva ou legislativa, de acordo com o poder do Estado competente para respondê-las. Algumas diretrizes demandam explicitamente criação, alteração ou regulamentação de legislação, o que só pode ser feito pelo Congresso Nacional. Outras, ainda que inicialmente direcionadas ao Poder Executivo, podem ser igualmente objeto de apreciação do Legislativo ${ }^{2}$.

Considera-se que uma diretriz resultante de CNPP (uma de suas deliberações finais, aprovada na etapa nacional) foi respondida quando alguma proposição legislativa com ela converge ou dela diverge, o que é medido pela variável sentido (positivo/negativo). O número de respostas analisadas pode, por isso, ser superior ao número efetivo de proposições legislativas pertinentes, visto que uma diretriz de CNPP pode ser respondida por mais de uma proposição legislativa, e uma mesma proposição legislativa pode responder a mais de uma diretriz.

Quanto ao segundo nível de análise da responsividade, a congruência temática, analisa-se a correspondência substantiva entre as diretrizes finais das conferências nacionais e as proposições legislativas do Congresso Nacional no mesmo período ${ }^{3}$. Foram consideradas proposições legislativas em trâmite ou arquivadas a partir de busca por palavraschaves ou frases-chaves contendo o núcleo substantivo de cada uma das diretrizes das CNPPs analisadas. As buscas foram feitas nos bancos de dados da Câmara dos Deputados e do Senado Federal, englobando todos os tipos de atos legislativos ${ }^{4}$. Duas variáveis são relevantes nesta análise: sentido e alcance. São consideradas congruentes (ou seja, têm sentido positivo) as proposições legislativas que respondem às diretrizes das CNPPs no exato sentido almejado, cumprindo o seu objetivo. São incongruentes ou divergentes (ou seja, têm sentido negativo) as proposições legislativas que rejeitam ou alteram o sentido das diretrizes das CNPPs, deixando de cumprir o seu objetivo. Quanto ao alcance, são consideradas integrais as proposições legislativas que responderam à totalidade da sua diretriz correspondente e parciais as que o fizeram somente em parte.

Por fim, a multimensionalidade da representação será analisada com base na distribuição das respostas do Poder Legislativo às diretrizes finais das CNPPs a partir de algumas variáveis, tais como as clivagens partidária (governo $x$ oposição) e ideológica (direta $x$ esquerda), além da autoria (Legislativo $x$ Executivo) das proposições legislativas. Res- 
salte-se que as diretrizes das CNPPs que compõem o banco de dados são aquelas que envolvem demandas que possam ser atendidas pelo Poder Legislativo, por estarem inseridas em sua esfera de competência, mesmo que tenham sido dirigidas primariamente ao Poder Executivo e, eventualmente, também possam ser atendidas por ele por meio de atos administrativos de competência da Administração Pública Federal (cf. Pogrebinschi, 2012c).

Para analisar os indicadores, utilizamos dados do banco ISEGORIA, montado a partir de pesquisas desenvolvidas desde 2010 no Laboratório de Estudos sobre a Democracia (LED) no IESP-UERJ. O banco de dados ISEGORIA contém as diretrizes finais de todas as conferências realizadas entre 1988 e 2010 que possuíram escopo nacional e produziram documento final contendo os resultados das deliberações havidas em tais espaços participativos. O banco também contém todas as proposições legislativas tramitadas no Congresso Nacional entre 1988 e 2010 que tratam dos temas aprovados nas diretrizes das CNPPs. A análise realizada neste artigo limita-se ao período correspondente aos dois primeiros mandados do presidente Luiz Inácio Lula da Silva (2003-2010), de modo a manterem-se minimamente constantes as condições de análise. Ademais, sabe-se que somente a partir de 2003 as CNPPs passaram a conformar um mecanismo de diálogo mais presente na relação entre Estado e sociedade no Brasil (Pogrebinschi e Santos, 2011; Pogrebinschi, 2012a; Avritzer e Souza, 2013), muito embora já tenha sido verificada a existência de impacto legislativo das CNPPs também no período anterior a 2003 (Pogrebinschi e Santos, 2011; Pogrebinschi e Samuels, 2014). Com base no recorte temporal e nos critérios que orientam a seleção de casos do banco de dados ISEGORIA (Pogrebinschi, 2010), o universo investigado neste artigo é composto de 60 CNPPs, 3.030 diretrizes delas resultantes e 1.661 proposições legislativas.

Caso seja possível demonstrar empiricamente que as CNPPs impactam de forma positiva a responsividade do Congresso Nacional, é razoável supor que inovações democráticas de natureza participativa e deliberativa, em geral, possam ampliar a responsividade de parlamentos e governos, aumentando a qualidade da democracia. Em outras palavras, se formas não eleitorais de participação mostrarem-se aptas a tornar as instituições representativas mais responsivas, é racional argumentar que a adoção de uma concepção mais abrangente e atual de participação seja essencial para avaliar efetivamente a qualidade das 
democracias contemporâneas. A demonstração empírica deste argumento é o que faremos a seguir.

\section{Impacto nas Políticas}

O Congresso Nacional respondeu às diretrizes das 60 CNPPs analisadas com um total de 2.976 respostas positivas e 158 respostas negativas $^{5}$. Dentre as positivas, respostas integrais somam 1.502 , o que indica que $50 \%$ das respostas legislativas atenderam à totalidade das demandas contidas em cada uma das diretrizes das CNPPs. Os números absolutos revelam já a existência de uma forte convergência de agenda entre legisladores e CNPPs, indicando a capacidade responsiva do Legislativo no que tange à proposição de políticas públicas que refletem as demandas expressas na arena participativa. O reduzido número de respostas negativas aponta uma pequena disposição $(5 \%)$ por parte do Legislativo para atuar de forma refratária às diretrizes das CNPPs ${ }^{6}$.

Considerando o ano das proposições legislativas congruentes com as diretrizes das CNPPs, as respostas distribuem-se temporalmente conforme exposto no Gráfico 1. É possível detectar um processo de crescimento do impacto legislativo no decorrer dos anos, tanto no que toca ao sentido positivo das respostas, quanto à sua integralidade. É possível supor, com base nos dados, que as respostas positivas crescem con-

\section{Gráfico 1}

Distribuição Temporal das Respostas

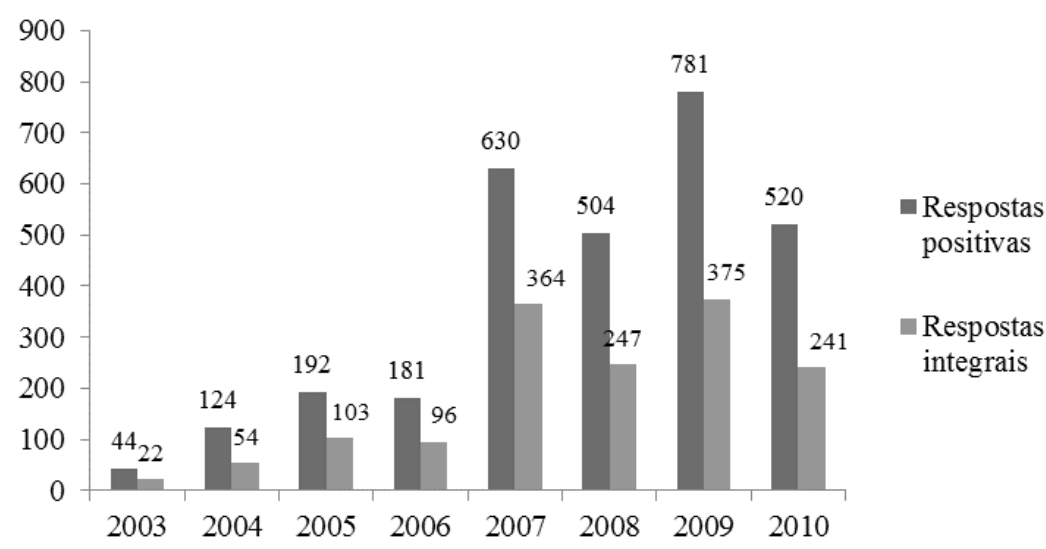

Fonte: ISEGORIA. Elaboração dos autores. 
forme as CNPPs se institucionalizam. As respostas do Legislativo caminham de forma crescente, tendo um grande salto a partir de 2007, no segundo mandato do presidente Lula. Este parece ser um tempo razoável para que as CNPPs ocorridas a partir de 2003 comecem a surtir efeito. Observa-se ainda que o volume de respostas em 2008 e em 2010, apesar de superior aos anos iniciais, não acompanha o crescimento encontrado em 2007 e 2009. Isso pode ser explicado pelo fato de que naqueles anos ocorreram eleições nacionais e municipais, o que tende a diminuir a produção legislativa do Congresso por conta do envolvimento dos parlamentares nas disputas eleitorais.

A distribuição das respostas com base nas áreas de políticas públicas tratadas nas CNPPs encontra-se no Gráfico 2. A categoria Minorias e Direitos Humanos, com 19 conferências realizadas, recebeu 1.460 respostas positivas e 853 integrais; a área de políticas para Saúde, com 10 CNPPs, teve 509 respostas positivas e 194 integrais; a categoria temática Estado e Desenvolvimento, com 18 CNPPs, teve 688 respostas positivas e 347 integrais; por fim, a área de políticas para Educação, Cultura, Assistência Social e Esporte, com 13 CNPPs, recebeu 319 respostas positivas e 108 integrais. O primeiro elemento a destacar-se na análise temática é o forte impacto da área de políticas sobre Minorias e Direitos Humanos. Isso confirma a capacidade inclusiva das CNPPs, conforme já destacado por Pogrebinschi (2013 e 2014), que vêm propiciando que as demandas de grupos minoritários se convertam em políticas e leis. Quando ativado pelas CNPPs, o Poder Legislativo parece ser especial-

\section{Gráfico 2}

Distribuição das Respostas por Áreas de Políticas

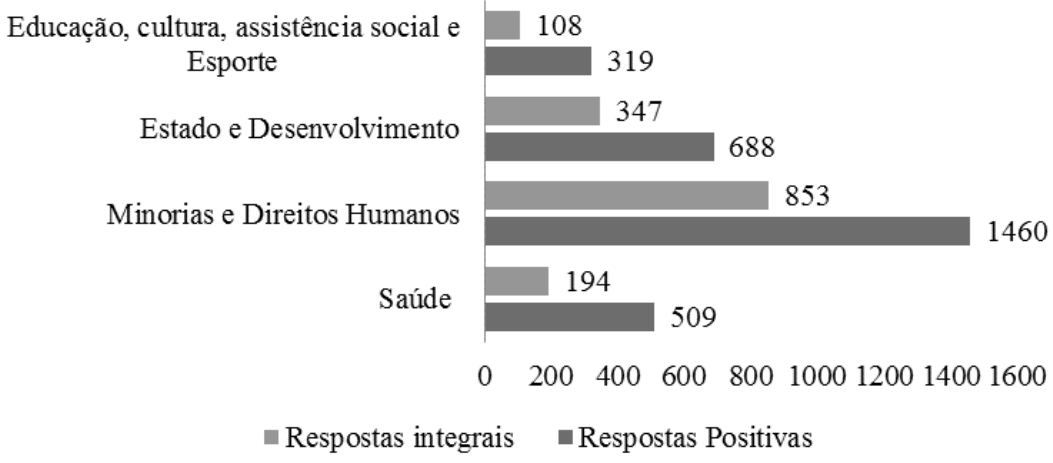

Fonte: ISEGORIA. Elaboração dos autores. 
mente responsivo às demandas de grupos historicamente sub-representados na política brasileira.

O segundo elemento que merece ser destacado é o impacto expressivo das CNPPs nas políticas de saúde. Levando em conta o número reduzido de CNPPs na área de saúde no período analisado, seu impacto legislativo pode ser considerado substantivo. Isso corrobora os achados iniciais de Pogrebinschi e Santos (2011), e pode ser explicado pelo histórico engajamento dos movimentos sociais da área de saúde e pela pujante institucionalização dos mecanismos de participação nessa área, que conta com milhares de conselhos municipais, além das primeiras e mais antigas CNPPs (Cortes, 2002; Escorel e Bloch, 2005).

Como o potencial impacto das CNPPs se distribui na produção legislativa brasileira? Qual o significado do volume de respostas, quando analisamos o número total de proposições legislativas tramitadas no Congresso Nacional? A Tabela 1 contém os dados relativos às respostas positivas, integrais e negativas, e sua comparação com o volume total da produção legislativa no período em análise. Os tipos legislativos analisados englobam projetos de lei, leis ordinárias e complementares, propostas de emenda constitucional (PECs) e emendas constitucionais.

Tabela 1

Distribuição das Respostas no Universo Total de Proposições Legislativas

\begin{tabular}{l|c|c|c|c}
\hline $\begin{array}{l}\text { Tipos } \\
\text { Legislativos }\end{array}$ & $\begin{array}{c}\text { Número de } \\
\text { Proposições } \\
\text { Respondidas } \\
\text { Positivamente } \\
\mathbf{( \% )}\end{array}$ & $\begin{array}{c}\text { Número de } \\
\text { Proposições } \\
\text { Respondidas } \\
\text { Integralmente } \\
\mathbf{( \% )}\end{array}$ & $\begin{array}{c}\text { Número de } \\
\text { Proposições } \\
\text { Respondidas } \\
\text { Negativamente } \\
\mathbf{( \% )}\end{array}$ & $\begin{array}{c}\text { Universo de } \\
\text { Proposiçóes } \\
\text { (2003-2010) }\end{array}$ \\
\hline $\begin{array}{c}\text { Projetos de lei } \\
\text { ordinária e } \\
\text { complementar }\end{array}$ & $1.477(7,2)$ & $841(4,1)$ & $81(0,04)$ & 20.238 \\
$\begin{array}{c}\text { Propostas de } \\
\text { emenda } \\
\text { constitucional }\end{array}$ & $126(7,7)$ & $80(5)$ & $16(0,09)$ & 1.632 \\
$\begin{array}{c}\text { Leis ordinárias e } \\
\text { complementares }\end{array}$ & $115(7,2)$ & $66(3,8)$ & $5(0,02)$ & 1.718 \\
$\begin{array}{c}\text { Emendas } \\
\text { constitucionais }\end{array}$ & $6(22)$ & $4(14,8)$ & 0 & 27 \\
\hline
\end{tabular}

Fonte: ISEGORIA. Elaboração dos Autores

No que tange às respostas positivas, foram identificados 1.477 projetos de lei ordinária e complementar, 126 propostas de emenda constitucio- 
nal, 115 leis ordinárias e complementares e 6 emendas constitucionais, dentre os quais 841 projetos de lei ordinária, 80 propostas de emenda constitucional (PECs), 66 leis ordinárias e complementares e quatro emendas constitucionais respondidos de forma integral. Em relação às respostas negativas, foram 81 projetos de lei ordinária, 16 propostas de emenda constitucional, 5 leis ordinárias e complementares e nenhuma emenda constitucional ${ }^{7}$.

Para avaliar o significado dos dados agregados quando tomados de forma comparada com o universo da produção legal do país, deve-se ponderar algumas questões. Em primeiro lugar, é preciso notar que a produção legislativa brasileira não se restringe à formulação de políticas públicas. O Congresso Nacional trata também de questões administrativas, dilemas federativos etc. Por isso, é preciso relativizar o impacto percentual das conferências quando se toma em consideração o universo total da produção legislativa. Sendo assim, os dados apontam a possibilidade de que as CNPPs convertam as demandas expressas em seus fóruns participativos e deliberativos em ação e produção legal nas instituições representativas, impactando a formulação de políticas públicas.

Em relação aos projetos de lei e leis ordinárias e complementares aprovados, foi encontrado um total de $7,2 \%$ de respostas às diretrizes das conferências, sendo que $4,1 \%$ e 3,8\%, respectivamente, atendem à integralidade das demandas das CNPPs. No que tange às PECs e emendas constitucionais, as taxas são de $7,7 \%$ e $22 \%$, respectivamente, em relação à convergência, e 5\% e 14\% em relação à integralidade. Os dois tipos legislativos em questão demonstram impacto significativo em relação às demandas das conferências. Em especial, apontam a força de sua capacidade de articulação no Congresso, visto que emendas constitucionais são um tipo de proposição cuja aprovação, mais laboriosa se comparada à legislação ordinária, exige alto grau de consenso (Pogrebinschi e Santos, 2011).

Esses dados iniciais mostram que as preferências expressas nas CNPPs estão refletidas de forma não desprezível na produção legislativa do Congresso Nacional. Vê-se que, ao invés de enfraquecer o Legislativo, instâncias participativas podem, na verdade, fortalecê-lo. Este resultado segue sentido contrário ao do argumento de que o Decreto Presidencial 8.243/14 que instituía o Sistema Nacional de Participação Social e a Política Nacional de Participação Social enfraqueceria o 
Congresso Nacional (Pogrebinschi, 2014). Não apenas os cidadãos e os atores coletivos têm mais espaços para vocalizar suas demandas, mas também os representantes eleitos por meio do voto têm mais oportunidades de conhecer as preferências de seus atuais e potenciais eleitores, transformando-as em políticas públicas. O primeiro nível de análise do conceito de responsividade mostra como, ao impactar a definição da agenda de políticas públicas, mecanismos participativos como as CNPPs podem tornar as instituições representativas mais responsivas.

\section{Congruência Temática}

A análise da segunda variável do modelo proposto para a responsividade consiste no exame substantivo das respostas legislativas, buscando identificar a existência de congruência temática (issue congruence) e não apenas convergência de agenda - com as demandas propostas nas CNPPs. As 60 CNPPs analisadas produziram um total de 3.030 diretrizes direcionadas ao Poder Legislativo, ou seja, demandas que recaem na esfera de competência do Congresso Nacional (e não, de forma exclusiva, na esfera de competência do Poder Executivo, por exemplo). Essas diretrizes são indicativo de que cidadãos e organizações da sociedade civil buscam, via inovações participativas, direcionar suas demandas ao Estado e ter suas preferências e opiniões atendidas por suas instituições. O volume de demandas expressamente direcionadas ao Poder Legislativo mostra que as instâncias participativas desejam se fazer ouvir e influir nas instituições representativas, e não se impor a elas ou substituí-las ${ }^{8}$.

De forma agregada, encontraram-se respostas a 890 diretrizes das CNPPs, o que contabiliza um total de $29,2 \%$ de demandas respondidas. Dentre as diretrizes respondidas, 865 receberam respostas positivas, perfazendo $28,5 \%$ do que denominamos taxa de congruência. Por outro lado, apenas 65 receberam respostas contrárias ao que fora demandado, resultando em taxa de divergência de $2 \%$. Vale registrar que uma mesma diretriz de CNPP pode receber simultaneamente resposta legislativa congruente e divergente, dado que ela pode ser objeto de diferentes proposições legislativas. Nota-se que perto de um terço do total de demandas dos participantes das CNPPs foi respondida positivamente pelo Legislativo, enquanto apenas $2 \%$ delas foram rejeitadas, relevando-se, assim, forte congruência temática entre as preferências expressas no fórum participativo e aquelas respondidas na arena legislativa. 
No entanto, apesar da congruência temática, vale registrar que em torno de $70 \%$ das demandas das conferências não receberam nenhum tipo de resposta do Poder Legislativo. Apesar de serem canais de razoável sucesso no direcionamento das demandas da sociedade perante o Legislativo, ainda há uma diferença importante no total das deliberações realizadas e sua efetivação. Defendemos aqui que, conforme aponta parte da literatura (Dagnino, 2002; Almeida e Tatagiba, 2012), deve-se evitar a superestimação das expectativas sobre os resultados das inovações participativas, pois essa postura ignora limites inerentes à sua natureza institucional. Nessa perspectiva, esperar que todas as deliberações das CNPPs se convertam em políticas ignora que as CNPPs são instâncias de colaboração no processo de produção de políticas públicas, no qual as preferências de outros agentes institucionais devem ser consideradas também.

As CNPPs com maior taxa de congruência foram a II Conferência Nacional de Saúde Mental (100\%), a I Conferência Nacional de Educação Profissional e Tecnológica (73,7\%), a I Conferência Nacional de Políticas Públicas para as Mulheres (71,2\%), a III Conferência Nacional de Meio Ambiente (60,9\%) e a IConferência Nacional de Ciência, Tecnologia e Inovação em Saúde (56,8\%). Tomando-se em consideração os números absolutos de diretrizes, as CNPPs mais receptivas foram a I e II Conferências de Políticas Públicas para Mulheres, com 122 e 42 diretrizes respondidas positivamente, a IX e XI Conferências de Direitos Humanos, com 29 e 80 diretrizes, e a II Conferência de Gestão do Trabalho e da Educação em Saúde, com 30.

Por sua vez, as CNPPs com maior taxa divergência são a XI Conferência Nacional de Direitos Humanos, com 11 diretrizes que receberam proposições legislativas divergentes, e a II Conferência Nacional de Políticas Públicas para Mulheres, com 12 diretrizes. Diversas das demandas são relacionadas a temas controversos como legalização do aborto ou garantia de direitos à população LGBT. O Gráfico 3 apresenta as taxas de congruência e divergência distribuídas com base em áreas de políticas públicas.

Nota-se que o elevado padrão de congruência entre as demandas participativas e as proposições legislativas se mantém quando os dados são desagregados por áreas de políticas públicas. Para todas as áreas analisadas, a taxa de diretrizes rejeitadas é quase inexpressiva e muito inferior à taxa de respostas congruentes. Duas áreas de políticas públicas destacam-se positivamente: Saúde e Estado e Desenvolvimento. O pri- 


\section{Gráfico 3}

Taxa de Congruência e Divergência por Áreas de Políticas Públicas

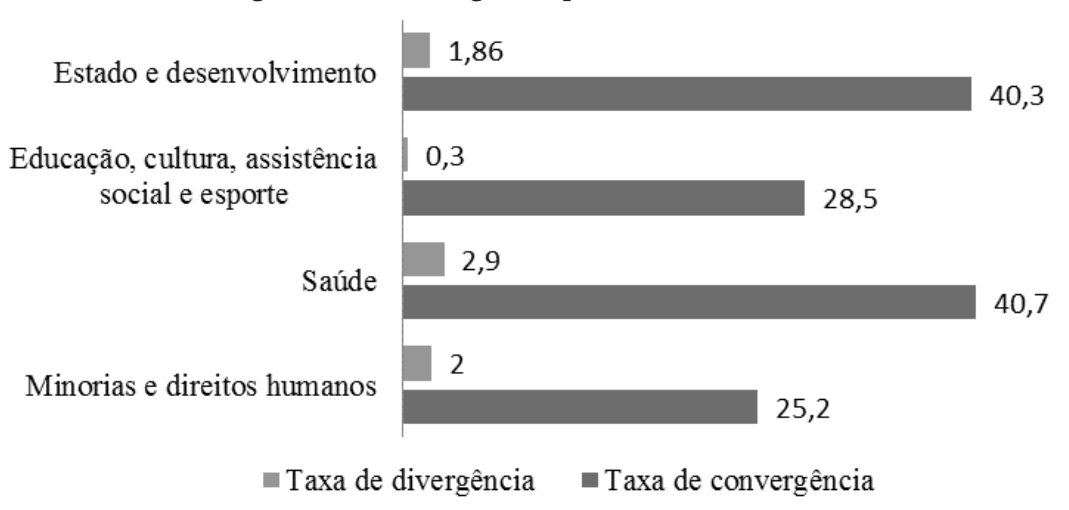

Fonte: ISEGORIA. Elaboração dos autores.

meiro caso confirma o alto grau de institucionalização das CNPPs de saúde, cuja antiga e extensa mobilização certamente já é conhecida pelos legisladores e por eles respeitada. O segundo caso indica o potencial das inovações participativas em impactar questões de infraestrutura, por exemplo, via CNPPs de Cidades, Segurança Pública, Meio Ambiente ou Recursos Humanos da Administração Federal. Isso indica que mecanismos participativos podem influenciar temas tradicionalmente associados ao conhecimento técnico e dominados por expertos, nos quais a participação da sociedade é tradicionalmente deixada de lado (Pogrebinschi, 2012a).

Do universo total de diretrizes, 513 foram respondidas em sua integralidade, ou seja, sem que nenhuma demanda fosse deixada de fora. Isso corresponde a $17 \%$ das demandas relativas às 60 CNPPs analisadas. Porém, considerando somente as diretrizes respondidas positivamente, essa proporção sobre para 59,3\%. Verifica-se que, a despeito da motivação dos legisladores, há congruência entre as demandas feitas na seara participativa e as políticas formuladas no Congresso Nacional sobre os mesmos temas. As CNPPs revelam-se potenciais adicionais de expressão das preferências dos cidadãos e dos diversos grupos sociais que, se ouvidas pelos legisladores, podem contribuir para a formulação de políticas mais responsivas.

\section{Multidimensionalidade da Representação}

O terceiro elemento do modelo proposto consiste na multidimensionalidade da representação. A pergunta a ser respondida aqui é a seguin- 
te: em que medida inovações participativas como as CNPPs podem tornar a representação política mais multidimensional e, assim, tornar o Poder Legislativo mais responsivo? Trata-se aqui de investigar se as CNPPs permitem uma expressão plural dos diversos partidos políticos com representação no Congresso Nacional, a despeito de sua posição no espectro ideológico (direita-esquerda) e de seu papel na coalizão de governo (oposição ou base governista). Ademais, busca-se investigar também se as proposições legislativas congruentes com as demandas das CNPPs têm sua origem no Poder Legislativo ou no Executivo. Isso permite investigar empiricamente a tese de que as CNPPs serviriam para que o Poder Executivo implementasse (e legitimasse) sua agenda, enfraquecendo o Poder Legislativo.

A análise será feita em duas etapas. Em primeiro lugar, examinaremos a origem das proposições legislativas congruentes com as recomendações das CNPPs, identificando se a autoria pertence ao Poder Executivo ou ao Poder Legislativo. Em seguida, serão analisados os partidos políticos que apresentaram proposições legislativas congruentes de acordo com o seu pertencimento à base governista no Congresso Nacional e à sua distribuição no eixo esquerda e direita (Power e Zucco Júnior, 2011) ${ }^{9}$. No eixo esquerda foram incluídos Partido dos Trabalhadores (PT), Partido Socialista Brasileiro (PSB), Partido Democrático Trabalhista (PDT) (2003-2010) e Partido Popular Socialista (PPS) (2003-2006); no centro foram computados Partido da Social Democracia Brasileira (PSDB), Partido do Movimento Democrático Brasileiro (PMDB) (2003-2010) e Partido Popular Socialista (PPS) (2007-2010); Partido da Frente Liberal (PFL)/Democratas (DEM), Partido Trabalhista Brasileiro (PTB), Partido Liberal (PL) / Partido da República (PR) e Partido Progressista (PP) (2003-2010) foram alocados na direita.

Serão adotadas duas metodologias distintas. Em primeiro lugar, será feita uma análise das estatísticas descritivas das variáveis (Tabela 2). Em segundo lugar, serão construídos seis modelos de regressão logística (Tabela 3), três em que a variável dependente será a resposta positiva ou negativa à demanda (sentido) e outros três nos quais a integralidade da resposta (grau) será a variável dependente ${ }^{10}$. Os modelos de regressão logística servem para medir duas questões. Primeiro, se alguma das variáveis independentes tem influência na resposta positiva ou negativa à diretriz da conferência; segundo, se, havendo resposta positiva, a chance de a mesma ser integral sofre alteração a partir dos elementos incluídos nos modelos. Os modelos possuem como variá- 
veis de controle a existência de pedido de urgência e o poder conclusivo das proposições em comissões legislativas.

Tabela 2

Análise Descritiva das Respostas

\begin{tabular}{|c|c|c|c|c|}
\hline Variáveis & & $\begin{array}{c}\text { Respostas } \\
\text { Congruentes (\%) } \\
\end{array}$ & \begin{tabular}{|c|} 
Respostas \\
Divergentes (\%)
\end{tabular} & $\begin{array}{c}\text { Respostas } \\
\text { Integrais (\%) }\end{array}$ \\
\hline Origem & $\begin{array}{l}\text { Poder Legislativo } \\
\text { Poder Executivo } \\
\text { Observações }\end{array}$ & $\begin{array}{c}2.755(90) \\
302(10) \\
2.969\end{array}$ & $\begin{array}{c}151(95,5) \\
7(4,5) \\
158\end{array}$ & $\begin{array}{c}1.356(90) \\
144(10) \\
1.500\end{array}$ \\
\hline Coalizão & $\begin{array}{l}\text { Governista } \\
\text { Oposição } \\
\text { Observações }\end{array}$ & $\begin{array}{c}1.836(69,7) \\
797(30,3) \\
2.633 \\
\end{array}$ & $\begin{array}{c}89(61) \\
57(39) \\
146\end{array}$ & $\begin{array}{c}930(68) \\
419(32) \\
1.349 \\
\end{array}$ \\
\hline $\begin{array}{l}\text { Quadro } \\
\text { Partidário* }\end{array}$ & $\begin{array}{l}\text { PT } \\
\text { PSDB } \\
\text { PMDB } \\
\text { PFL/DEM } \\
\text { PDT } \\
\text { PSB } \\
\text { PTB } \\
\text { PP } \\
\text { PPS } \\
\text { PL/PR } \\
\text { Observações }\end{array}$ & $\begin{array}{c}597(26,3) \\
297(13,2) \\
357(15,7) \\
241(10,6) \\
163(7,1) \\
209(9,2) \\
56(2,5) \\
119(5,3) \\
55(2,5) \\
170(7,6) \\
2.264\end{array}$ & $\begin{array}{c}6(4,6) \\
19(14,3) \\
35(26,4) \\
18(13,6) \\
7(5,4) \\
11(8,4) \\
8(6,2) \\
15(11,4) \\
5(3,7) \\
8(6) \\
132 \\
\end{array}$ & $\begin{array}{c}286(25) \\
144(12,6) \\
173(13,7) \\
144(12,6) \\
98(8,6) \\
100(8,7) \\
26(2,2) \\
51(4,5) \\
23(2) \\
93(8,1) \\
1.138 \\
\end{array}$ \\
\hline $\begin{array}{l}\text { Esquerda- } \\
\text { Direita }\end{array}$ & $\begin{array}{l}\text { Esquerda } \\
\text { Direita } \\
\text { Centro } \\
\text { Observações }\end{array}$ & $\begin{array}{c}982(43,3) \\
586(25,8) \\
696(30,7) \\
2.264\end{array}$ & $\begin{array}{c}24(18,1) \\
49(37,1) \\
59(44,6) \\
132\end{array}$ & $\begin{array}{c}490(43,3) \\
314(27,5) \\
334(29,3) \\
1.138\end{array}$ \\
\hline
\end{tabular}

Fonte: ISEGORIA. Elaboração dos autores.

* Foram considerados somente os dez maiores partidos com representação no Congresso, o que corresponde a aproximadamente $87 \%$ do universo total de respostas.

Os dados revelam que a maior parte das respostas são de iniciativa do Poder Legislativo. A taxa de proposições legislativas congruentes e integrais é semelhante, correspondendo a aproximadamente $90 \%$ para iniciativa do Legislativo e 10\% para iniciativa do Executivo. Tais achados são reveladores. Se a quase a totalidade das proposições legislativas congruentes com as demandas das CNPPs são apresentadas por membros do Congresso Nacional, torna-se possível discordar com base em dados empíricos do argumento de que essas instâncias participativas são instrumentalizadas pelo Poder Executivo. Mais ainda, o dado de que $30 \%$ das respostas positivas e $32 \%$ das respostas congruentes foram apresentadas por partidos da oposição demonstram que esses também respondem às CNPPs, reforçando os argumentos contrários à tese da instrumentalização desses espaços participativos. 
No caso das respostas divergentes, o número de proposições de iniciativa do Poder Legislativo é ainda maior, 95,5\%. Vê-se que o Congresso Nacional logra rejeitar demandas das CNPPs quando isso lhe convém, apresentando proposições legislativas contrárias ao demandado na arena participativa. A diferença de 5,5\% detectada entre as respostas divergentes e congruentes iniciadas pelo Poder Legislativo, contudo, não é estatisticamente significante, conforme revela o teste exposto na Tabela 3, modelo I. Ou seja, essa diferença percentual não permite afirmar que o Poder Legislativo tenha probabilidade maior de responder de forma contrária às demandas das CNPPs. Também não há diferença no que tange à autoria quando se analisa a integralidade das respostas congruentes, conforme se verifica no modelo II, exposto na Tabela 3. Independentemente de a autoria ser do Executivo ou do Legislativo, as respostas convergentes possuem chance semelhante de atenderem integralmente às demandas das CNPPs.

Tabela 3

Modelos de Regressão Logística (I, II, III, IV)

\begin{tabular}{l|c|c|c|c|c|c}
\hline $\begin{array}{l}\text { Variáveis } \\
\text { Independentes }\end{array}$ & $\begin{array}{c}\text { Modelo I } \\
\text { Coeficiente }\end{array}$ & $\begin{array}{c}\text { Modelo II } \\
\text { Coeficiente }\end{array}$ & $\begin{array}{c}\text { Modelo III } \\
\text { Coeficiente }\end{array}$ & $\begin{array}{c}\text { Modelo IV } \\
\text { Coeficiente }\end{array}$ & $\begin{array}{c}\text { Modelo V } \\
\text { Coeficiente }\end{array}$ & $\begin{array}{c}\text { Modelo VI } \\
\text { Coeficiente }\end{array}$ \\
\hline Poder conclusivo & $0,90^{* * *}$ & $-0.43^{* * *}$ & $0,82^{* * *}$ & $-0,47^{* * *}$ & $0,85^{* * *}$ & $-0,46^{* * *}$ \\
Pedido de & $0,90^{* * *}$ & $-0,18$ & $0,86^{* *}$ & $-0,23^{*}$ & $0,87^{* *}$ & $-0,20$ \\
urgência & & & & & & \\
Origem & 0,60 & $-0,15$ & & & & \\
Base do governo & & & 0,32 & 0,32 & 0,31 & $-0,14$ \\
PSDB & & & $-1,42^{*}$ & 0,18 & & \\
PMDB & & & $-2,14^{* * *}$ & $-0,18$ & & \\
PFL/DEM & & & $-1,45^{*}$ & $0,60^{*}$ & & \\
PDT & & $-1,07$ & $0,50^{* *}$ & & \\
PSB & & $-1,57^{* *}$ & $-0,07$ & & \\
PPS & & $-1,82^{*}$ & $-0,16$ & & \\
PP & & $-2,28^{* * *}$ & $-0,42^{*}$ & & \\
PL/PR & & $-1,39^{*}$ & 0,11 & & \\
PTB & & $-2,5^{* *}$ & $-0,31$ & & \\
Esquerda & & & & & $1,21^{* * *}$ & 0,09 \\
Centro & & & & & $-0,09$ & $-0,21$ \\
\hline
\end{tabular}

Fonte: ISEGORIA. Elaboração dos autores.

Obs.: Modelos I, II e V tomam a variável sentido como dependente, e os Modelos III, IV e VI tomam a variável grau. Significante ao nível de $99,9 \%\left(^{* * *}\right), 99 \%\left(^{* *}\right)$ e $95 \%(*)$. O PT é a categoria de referência para comparação com o restante dos partidos políticos nos modelos III e IV. A categoria "Direita" é a referência de comparação nos modelos V e VI.

Os dados iniciais apontam potencial das CNPPs para fortalecer o Poder Legislativo, que se revela como principal lócus da recepção das demandas expressas em tais instâncias participativas. No tradicional 
contexto de dependência do Legislativo vis-à-vis o Executivo, marca consagrada do presidencialismo de coalizão brasileiro (Abranches, 1988), é válido sublinhar o potencial das CNPPs para servir como instrumento de fortalecimento institucional do Legislativo. Tal conclusão condiz, embora por caminho diverso, com a proposição de Thamy Pogrebinschi e Fabiano Santos (2011), que identificarem nas CNPPs potencial para equilibrar diferenças informacionais entre Poder Executivo e Poder Legislativo.

Desagregando os dados e considerando apenas a legislação aprovada (leis ordinárias, leis complementares e emendas à Constituição), observa-se que $56 \%$ das respostas positivas têm iniciativa no próprio Poder Legislativo e $44 \%$ no Poder Executivo. Levando em conta que cerca de $85 \%$ de toda legislação aprovada pelo Congresso Nacional (1988-2006) tem iniciativa no Poder Executivo (Limongi, 2006), os dados em questão indicam que, quando a agenda do Legislativo converge com a agenda das CNPPs (e, portanto, da sociedade civil), o Congresso Nacional tem mais chances de ver aprovados os projetos de sua própria autoria, isto é, aqueles iniciados em uma de suas duas casas.

Em relação ao quadro partidário, o maior índice de respostas positivas é do PT (26,2\%), seguido de PMDB (15,7\%), PSDB (13,2\%) e PFL/DEM $(10,6 \%)$. Dentre as respostas divergentes, a presença do PT diminui consistentemente, e é acompanhada de um aumento na maioria dos outros partidos, com exceção de PDT, PSB e PL/PR. Todos os outros (com destaque para o PMDB, cuja ampliação é de 10,7\%) aumentam sua presença quando comparamos respostas convergentes/divergentes. Quanto à integralidade, o PT (25\%) volta a ser o mais expressivo, seguido de PMDB (13,7\%), PSDB (12,6\%) e PFL/DEM (12,6\%). Quanto à posição dos partidos em relação ao governo, os dados indicam que $69 \%$ e $68 \%$ das respostas positivas e integrais, respectivamente, são de parlamentares de partidos que fazem parte da coalizão governista. Ao considerarmos as respostas divergentes, essa taxa sofre uma pequena diminuição para $60 \%$.

Os dados indicam ainda que os maiores partidos das casas legislativas são também aqueles que mais respondem às recomendações das CNPPs. Os quatro maiores partidos eleitos em 2003 e 2007 são protagonistas nos quesitos respostas positivas e respostas integrais. Nesse ponto, o que chama atenção é a proeminência do PT em relação aos outros partidos, visto que seu protagonismo nas respostas legislativas às 
demandas das CNPPs é maior que a diferença de tamanho das bancadas legislativas dos maiores partidos do Congresso. Isso se explica pelos fortes laços que o PT possui com a sociedade civil desde a redemocratização e pela valorização que o partido dá aos mecanismos de participação social (Samuels, 2012 e Pogrebinschi, 2012). Isso explica também porque o PT é autor de uma proporção menor de respostas divergentes. O compromisso histórico do partido com a sociedade civil e seu compromisso programático com a participação social inclinam o partido a endossar demandas provenientes das CNPPs, as quais concebem como peça de um novo método de tomada de decisões políticas (Pogrebinschi, 2012b).

A proeminência do PT no que tange às respostas convergentes e divergentes é medida e confirmada pelo modelo III, ainda na Tabela 3. Os coeficientes dos modelos de regressão que comparam o PT com os oito maiores partidos do Congresso possuem significância estatística, com exceção da comparação com o PDT. Verifica-se que o PT responde mais, e o faz mais de forma convergente às demandas das CNPPs. O único partido com comportamento similar é o PDT, que tende também a responder mais positivamente. Nesse modelo, também foi incluída a variável que mede a participação dos parlamentares na base do governo, verificando-se que o pertencimento à coalização majoritária não possui significância estatística no que se refere às chances dos parlamentes responderem positivamente às demandas das CNPPs.

A preponderância do PT no volume de respostas não diminui a multidimensionalidade do impacto legislativo das CNPPs. Quando se considera o cômputo geral das respostas às demandas das Conferências (convergentes e integrais), nota-se que o partido é responsável por apenas $26 \%$, ou seja, cerca de um quarto do total de respostas. Trata-se de quase o mesmo percentual encontrado pela soma das respostas convergentes e integrais dos dois principais partidos políticos da oposição (PSDB e DEM/PFL), qual seja, 24\%. Portanto, a preponderância do PT não significa que outros partidos com diferentes orientações ideológicas e alinhamentos políticos não contribuam para a produção de respostas legislativas congruentes com as demandas das CNPPs.

Os resultados do modelo IV da regressão logística também reforçam a tese da multidimensionalidade da representação. Seu resultado indica que não há diferença significativa quando se tomam as respostas integrais como variável dependente comparando a participação do PT 
com a de partidos com maior bancada. As exceções são PDT, $\mathrm{PFL} / \mathrm{DEM}$ e PP, tendo os dois primeiros mais chance de responder de forma integral às demandas das CNPPs e o último menor chance de atuar de forma responsiva. Essa evidência reforça ainda mais a hipótese da multidimensionalidade, visto que PFL/DEM e PDT ocupam espaços distintos no que tange à distribuição ideológica dos partidos, sendo o primeiro posicionado mais à direita do espectro político e o segundo na centro-esquerda. O PP, que ocupa espaço ideológico próximo ao PFL/DEM, possui padrão oposto de atuação, tendendo a não produzir respostas integrais às demandas propostas nas CNPPs.

Por fim, resta avançar na análise da distribuição dos dez maiores partidos no eixo unidimensional esquerda-direita. A análise dessa variável é fundamental para verificar o potencial das CNPPs para ampliar a multidimensionalidade na dinâmica política brasileira, impulsionando partidos que ocupam distintas posições no espectro ideológico a responder às demandas feitas de forma participativa pela sociedade civil. Para todas as três categorias de respostas observa-se na Tabela 2 que a esquerda se sobressai em relação ao centro e à direita, com aproximadamente $43 \%$ do total das respostas convergentes e integrais e somente $18 \%$ de respostas divergentes. O posicionamento do PT à esquerda do espectro político explica esse padrão de respostas. Vale ressaltar, contudo, que, tanto em relação às respostas convergentes quanto às integrais, os partidos de esquerda não conformam maioria absoluta, sendo superados pelo cômputo agregado dos partidos de centro e de direita.

De forma análoga ao que sucedeu com as variáveis anteriores, foram elaborados dois modelos de regressão logística para verificar se há diferença significativa na razão de chance de os partidos políticos posicionados em grupos diferentes do espectro ideológico atuarem de forma responsiva às demandas das CNPPs. Aqui, assim como na análise do quadro partidário, verifica-se que, agregados, os partidos de esquerda tendem a responder de forma mais convergente se comparados aos partidos de centro e aos de direita. No entanto, percebe-se que não há diferença na atuação de partidos posicionados no centro e à direita do espectro ideológico, o que indica que o padrão de atuação em relação às demandas das CNPPs e sua inclusão ou rejeição na agenda legislativa não se altera quando os partidos políticos se posicionam mais à direita. Por fim, quando se toma a variável grau como dependente para o modelo de regressão, não se verifica diferença entre os grupos parti- 
dários, indicando que, no caso de respostas positivas, não há diferença estatisticamente significativa entre esquerda, direita e centro. Todos têm a mesma chance de responder de forma integral às demandas das CNPPs.

A análise empírica confirma a hipótese de que as Conferências Nacionais de Políticas Públicas impulsionam a multidimensionalidade da representação política, mesmo considerando a proeminência do PT e dos partidos de esquerda no cômputo das respostas convergentes e integrais e sua baixa participação nas respostas divergentes. Competição eleitoral e participação política caminham juntas sem que haja necessariamente um trade-off. As CNPPs podem ampliar a multidimensionalidade da representação, aumentando o repertório de ação dos representantes eleitos e permitindo que formulem políticas mais responsivas às preferências da sociedade.

\section{CONSIDERAÇÕES FINAIS}

Este artigo buscou demonstrar como inovações democráticas, por meio da participação de cidadãos e de atores da sociedade civil, podem tornar as instituições representativas mais responsivas e, assim, ampliar a qualidade das democracias contemporâneas. Para tanto, formulou-se um modelo de análise do conceito de responsividade a partir de três níveis: impacto nas políticas públicas, congruência temática e igualdade e multidimensionalidade da representação.

Foram apresentados dados relativos à influência das Conferências Nacionais de Políticas Públicas no ciclo de políticas públicas cruzando as demandas oriundas dessas arenas participativas com as proposições legislativas do Congresso brasileiro no período 2003-2010. Em relação ao impacto nas políticas públicas, os dados apontam o total de 1.661 proposições legislativas que respondem às demandas das CNPPs, número relevante quando comparado à produção legislativa do Congresso no período. No que tange à congruência temática, os dados indicam que a produção legislativa do período é congruente com um terço das diretrizes aprovadas nas CNPPs, uma taxa alta, considerando que as Conferências realizadas no período produziram 3.030 deliberações. Por fim, verificou-se que a multimensionalidade da representação é estimulada pelas CNPPs: os dados mostram o fortalecimento do Legislativo diante da agenda do Executivo e uma grande pluralidade nas res- 
postas advindas de partidos que ocupam distintas posições no eixo direita-esquerda, a despeito de um maior protagonismo do PT.

Os dados e testes empíricos realizados mostram, de uma forma geral, que as CNPPs tornam o Congresso Nacional mais responsivo. Os espaços participativos permitem que os representantes eleitos por meio do voto conheçam mais e melhor as preferências da sociedade, aumentando as chances de formularem políticas que a contemple ou dela se aproxime. A constatação de que partidos de orientações ideológicas distintas convergem em torno da agenda de políticas demandada pela sociedade civil indica que inovações democráticas como as CNPPs têm potencial de somar representação e participação agregando mais qualidade à democracia.

(Recebido para publicação em abril de 2015)

(Reapresentado em agosto de 2016) (Aprovado para publicação em janeiro de 2017) 


\section{NOTAS}

1. Vale destacar que as CNPPs, apesar de estarem agregadas sob essa definição comum, variam em aspectos relativos ao seu desenho institucional, em questões relativas a eleição de delegados, composição da comissão organizadora, forma de convocação, organização das etapas locais, entre outros. Para uma discussão sobre tais características e a efetividade das CNPPs ver Pogrebinschi e Ryan (2014).

2. Cf. Pogrebinschi (2010) para maior detalhamento teórico e metodológico sobre o conceito de diretrizes legislativas e executivas e seu tratamento empírico para a composição do banco de dados utilizado neste artigo.

3. Os dados referem-se ao dia imediatamente posterior à realização da conferência em questão até o dia 19 de outubro de 2010.

4. Neste caso, os dados também referem-se ao dia imediatamente posterior à realização da conferência em questão até o dia 19 de outubro de 2010.

5. O conceito respostas não deve ser confundido com o total de atos legislativos. Por exemplo, um projeto de lei pode responder a mais de uma diretriz aprovada em determinada CNPP, gerando, assim, mais de uma resposta.

6. Dentre as CNPPs de maior impacto, destacam-se a I e II Conferência de Políticas Públicas para as Mulheres, com 452 e 261 respostas positivas, respectivamente; a XI Conferência de Direitos Humanos, com 253; a I Conferência de Cidades, com 137; e a II Conferência de Gestão do Trabalho e da Educação em Saúde, com 133 respostas positivas. Dentre as CNPPs que receberam maior número de respostas divergentes, destacam-se a I Conferência de Políticas Públicas para as Mulheres, com 17 respostas negativas; a IX, X e XI Conferência de Direitos Humanos, com 23, 29 e 22, respectivamente; e a III Conferência de Segurança Alimentar e Nutricional, com 12 respostas negativas. No que tange às respostas integrais destacam-se a I e II Conferência de Políticas Públicas para as Mulheres, com 146 e 291, respectivamente; a XI Conferência de Direitos Humanos, com 83; a I Conferência de Cidades, com 133; e a I Conferência de Juventude, com 57.

7. Estão agrupadas nesses dados informações relativas às proposições da Câmara dos Deputados e do Senado.

8. Esse é mais um dado capaz de comprovar como falsas as discussões sobre o decreto 8.243/2014, que propôs a criação do Sistema Nacional de Participação Social, e as assertivas de que conferências e conselhos nacionais iriam sobrepujar a ação e a liberdade do Poder Legislativo brasileiro.

9. Foram utilizadas as médias das estimativas construídas por Power e Zucco Júnior (2011) para estimar a ideologia dos congressistas brasileiros para os anos de $2005 \mathrm{e}$ 2009 com base no survey realizado nesses anos. Nesse caso, para poder operacionalizar os dados estimou-se pontos de corte para agrupar os partidos em três grupos: esquerda, centro e direita. Como as estimativas das médias construídas pelos autores variam de 1-10, estimou-se, para os fins deste artigo, os valores de 1-4 para o conjunto de partidos da esquerda, englobando PT, PSB, PDT e PPS; 5-6 para o centro, com os partidos PSDB, PMDB e PPS; e 7-10 para a direita, com PTB, PP, PL/PR e PFL/DEM. Nesse caso, não houve variação entre os grupos na maioria dos partidos, com exceção do PPS, que saltou da esquerda para o centro entre os surveys de 2005 e 2009. Vale ressaltar também que foram considerados nas pesquisas somente os dez maiores 
partidos no Parlamento nas duas legislaturas em análise. Optamos por restringir em um ponto na escala de Power e Zucco Júnior a medida para o grupo do centro, ampliando o grupo dos partidos da direita como mecanismo para lidar com o fenômeno da “Direita Envergonhada" indicado pelos autores (Power e Zucco Júnior, 2011:43).

10. Os modelos I, III e V usam a variável sentido como dependentes. Já os modelos II, IV e VI, utilizam a variável grau. 


\section{REFERÊNCIAS BIBLIOGRÁFICAS}

ABRANCHES, Sérgio Henrique. (1998), "Presidencialismo de Coalizão: O Dilema Institucional Brasileiro". DADOS - Revista de Ciências Sociais, vol. 31, no 1, pp. 5-34.

ALMEIDA, Carla; TATAGIBA, Luciana. (2012), “Os Conselhos Gestores sob o Crivo da Política: Balanço e Perspectivas”. Serviço Social e Sociedade, no 109, pp. 68-92.

ALONSO, Sonia; MERKEL, Wolgang; KEANE, John. (2011), The Future of Representative Democracy. Cambridge, Cambridge University Press.

ALTMAN, David; PÉREZ-LIÑAN, Anibal. (2002), “Assessing the Quality of Democracy: Freedom, Competitiveness, and Participation in Eighteen Latin American Countries". Democratization, vol. 9, no 2, pp. 85-100.

AVRITZER, Leonardo. (2002), Democracy and the Public Space in Latin America. Princeton, Princeton University Press.

. (2009), Participatory Institutions in Democratic Brazil. Baltimore, Johns Hopkins University Press.

. (2010), Experiências Nacionais de Participação Social. São Paulo, Cortez.

; SOUZA, Clovis Henrique Lima (orgs.). (2013), Conferências Nacionais: Atores, Dinâmicas Participativas e Efetividade. Brasília, Ipea.

BAIOCCHI, Gianpaolo. (2003), Radicals in Power: The Workers' Party and Experiments in Urban Democracy in Brazil. London, Zed Books.

BARBER, Benjamin. (2004), Strong Democracy. Participatory Politics for a New Age. Berkeley, University of California Press.

BOHMAN, James. (1998), "The Coming of Age of Deliberative Democracy". Journal of Political Philosophy, vol. 6, pp. 400-425.

CASTIGLIONE, Dario; WARREN, Mark. (2006), Rethinking Representation: Eight Theoretical Issues. Trabalho apresentado na Conference on Rethinking Democratic Representation, University of British Columbia, Vancouver, 18-19 de maio.

CORTES, Soraya Maria Vargas. (2002), “Construindo a Possibilidade da Participação dos Usuários: Conselhos e Conferências no Sistema Único de Saúde". Sociologias, no 7, pp. 18-49.

CROZIER, Michael; HUNTINGTON, Samuel; WATANUKI, Joji. (1975), The Crisis of Democracy: On the Governability of Democracies. New York, New York University Press.

DAHL, Robert. (1971), Polyarchy: Participation and Opposition. New Haven/London, Yale University Press.

DIAMOND, Larry; MORLINO, Leonardo (orgs.). (2005), Assessing the Quality of Democracy. Baltimore, The Johns Hopkins University Press.

DONAGHY, Maurren. (2011), “Do Participatory Governance Institutions Matter? Municipal Councils and Social Housing Programs in Brazil". Comparative Politics, vol. 44, pp. 83-102.

DRYZEK, John S. (2000), Deliberative Democracy and Beyond: Liberals, Critics, Contestations. Oxford, Oxford University Press.

DADOS - Revista de Ciências Sociais, Rio de Janeiro, vol. 60, nº 1, 2017 


\section{Thamy Pogrebinschi e Tiago Ventura}

ESCOREL, Sarah; BLOCH, Renata Arruda de. (2005), “As Conferências Nacionais de Saúde na Construção do SUS", in N. T. Lima et al. (orgs.), Saúde e Democracia: História e Perspectivas do SUS. Rio de Janeiro, Fiocruz, pp. 83-118.

EULAU, Heinz; KARPS, Paul. (1977), “The Puzzle of Representation: Specifying Components of Responsiveness". Legislative Studies Quarterly, vol. 2, no 3, pp. 233-254.

FISHKIN, James. (1991), Democracy and Deliberation: New Directions for Democratic Reform. New Haven, Yale University Press.

FUNG, Archon; WRIGHT, Erik Olin. (2003), Deepening Democracy: Institutional Innovations in Empowered Participatory Governance. London, Verso.

GEISSEL, Brigitte. (2009), "How to Improve the Quality of Democracy? Experiences with Participative Innovations at the Local Level in Germany". German Politics and Society, vol. 27, no 4, pp. 51-71.

; JOAS, Marko. (2013), Participatory Democratic Innovations in Europe: Improving the Quality of Democracy?. Opladen/Berlin/Toronto, Barbara Budrich Publishers.

_ ; NEWTON, Keneth. (orgs). (2012), Evaluating Democratic Innovations: Curing the Democratic Malaise? London/New York, Routledge.

GOERTZ, Gary. (2006), Social Science Concepts: A User's Guide. Princeton, NJ, Princeton University Press.

GURZA LAVALLE, Adrian; HOUTZAGER, Peter; CASTELLO, Graziella. (2006), “Democracia, Pluralização da Representação e Sociedade Civil". Lua Nova, no 67, pp. 49-103.

GUTMANN, Amy. (2004), Why Deliberative Democracy? Princeton, Princeton University Press.

HABERMAS, Jürgen. (1975), Legitimation Crisis. Boston, Beacon Press.

. (1989), The Structural Transformation of the Public Sphere. Cambridge, UK, Polity.

HAYWARD, Jack. (1996), The Crisis of Representation in Europe. London, Routledge.

HUBER, John; POWELL, G. Bingham. (1994), “Congruence between Citizens and Policymakers in Two Visions of Liberal Democracy". World Politics, vol. 46, no 3, pp. 291-326.

KAASE, Max; NEWTON, Kenneth. (2005), Beliefs in Government. Oxford, Oxford University Press.

KATZ, Gabriel; MORLINO, Leonardo. (2013), What Qualities of Democracy in Latin America? Rome.

KOCHLER, Hans. (1987), The Crisis of Representative Democracy. Bern, Peter Lang GmbH.

LAUTH, Hans-Joachim. (2004), Demokratie und Demokratiemessung. Eine konzeptionelle Grundlegung für den interkulturellen Vergleich. Wiesbaden, VS Verlag für Sozialwissenschaften.

LEVINE, Daniel H.; MOLINA, José E. (2011), The Quality of Democracy in Latin America. Boulder, CO, Lynne Rienner Publishers.

LIJPHART, Arend. (1999), Patterns of Democracy: Government Forms and Performance in Thirty-Six Countries. New Haven, Yale University Press. 
LIMONGI, Fernando. (2006), “A Democracia no Brasil: Presidencialismo, Coalizão Partidária e Processo Decisório”. Novos Estudos, no 76, pp. 17-41.

LINZ, Juan J.; STEPAN, Alfred. (1978), The Breakdown of Democratic Regimes. Baltimore, Johns Hopkins University Press.

LÜCHMANN, Ligia Helena Hahn. (2007), “A Representação no Interior das Experiências de Participação". Lua Nova, no 70, pp. 139-170.

LUPIA, Arthur; McCUBINS, Mathew D. (1988), The Democratic Dilemma: Can Citizens Learn what They Need to Know? Cambridge, Cambridge University Press.

MANIN, Bernard; PRZEWORSKI, Adam; STOKES, Susan. (1999), Democracy, Accountability and Representation. New York, Cambridge University Press.

MANSBRIDGE, Jane. (1983), Beyond Adversary Democracy. Chicago, University of Chicago Press.

MAYHEW, David. (1974), Congress: The Electoral Connection. New Haven, CT, Yale University Press.

MAZZUCA, Sebastián. (2010), “Access to Power versus Exercise of Power: Reconceptualizing the Quality of Democracy in Latin America". Studies in Comparative Development, vol. 45, no 3, pp. 334-357.

MERKEL, Wolfgang. (2014), "Ist die Krise der Demokratie eine Erfindung?", in M. Reder; M-D. Cojocaru (orgs.), Zukunft der Demokratie: Ende einer Illusion oder Aufbruch zu neuen Formen? Stuttgart, Kohlhammer, pp. 25-46.

MORLINO, Leonardo. (1998), Democracy between Consolidation and Crisis. Parties, Groups, and Citizens in Southern Europe. Oxford, Oxford University Press.

. (2011), Changes for Democracy. Actors, Structures and Processes. Oxford, Oxford University Press.

MUNCK, Gerardo; VERKUILEN, Jay. (2002), “Conceptualizing and Measuring Democracy: Evaluating Alternative Indices". Comparative Political Studies, vol. 35, no 1, pp. 5-34.

MUNCK, Gerardo L. (2016), "What is Democracy? A Reconceptualization of the Quality of Democracy". Democratization, vol. 23, no 1, pp. 1-26.

O'DONNELL, Guillermo; VARGAS CULLELL, Jorge; IAZZETTA, Osvaldo (eds.). (2004), The Quality of Democracy. Theory and Applications. Notre Dame, IN, University of Notre Dame Press.

PATEMAN, Carole. (1970), Participation and Democratic Theory. Cambridge University Press.

PIRES, Roberto Rocha (org.). (2011), A Efetividade das Instituições Participativas no Brasil: Perspectivas, Abordagens e Estratégias de Avaliação. (Série Diálogos para o Desenvolvimento). Brasília, Ipea.

POGREBINSCHI, Thamy. (2010), Entre Participação e Representação: As Conferências Nacionais e o Experimentalismo Democrático Brasileiro. Relatório Final da Pesquisa Brasília, Ministério da Justiça do Brasil.

DADOS - Revista de Ciências Sociais, Rio de Janeiro, vol. 60, nº 1, 2017 


\section{Thamy Pogrebinschi e Tiago Ventura}

. (2012a), Participação como Método Democrático de Gestão. As Conferências Nacionais de Políticas Públicas durante o Governo Lula. Trabalho apresentado no Brazilian Studies Programme, Oxford University, 27 de janeiro.

. (2012b), “Com a Palavra a Sociedade". Insight Inteligência, vol. 54, pp. 90-99.

. (2012c), Conferências Nacionais e Políticas Públicas para Grupos Minoritários. Brasília, IPEA.

. (2013), Democratic Innovations and Quality of Democracy: Do we Need New and More Creative Recipes? Trabalho apresentado no encontro anual da European Consortium for Political Research. Bourdeaux, 4-7 de setembro.

(2014), "Novo Decreto. Não há Participação sem Representação". Carta Maior. Disponível em http:/ / www.cartacapital.com.br/politica/novo-decreto-nao-ha-representacao-sem-participacao-9169.html. Acesso em 16/5/2015.

; RYAN, Matt. (2014), Designing Impact: How Democratic Innovations may (or not) Achieve Effectiveness? Trabalho apresentado no Encontro Anual do European Consortium of Political Research (ECPR). Glasgow, Scotland, 4 de setembro.

; SAMUELS, David. (2014), “The Impact of Participatory Democracy: Evidence from Brazil's National Public Policy Conferences". Comparative Politics, vol. 46, no 3, pp. 313-332.

; SANTOS, Fabiano. (2011), "Participação como Representação: O Impacto das Conferências Nacionais de Políticas Públicas no Congresso Nacional". DADOS - Revista de Ciências Sociais, vol. 54, no 3, pp. 259-305.

POWELL, G. Bingham. (2004), “The Chain of Responsiveness". Journal of Democracy, vol. 15, no 4, pp. 91-105.

POWER, Timothy; ZUCCO JÚNIOR, Cesar (orgs.). (2011), O Congresso por Ele Mesmo: Autopercepções da Classe Política Brasileira. Belo Horizonte, UFMG Editora.

RIKER, William H. (1980), “Implications from the Disequilibrium of Majority Rule for the Study of Institutions". American Political Science Review, vol. 74, no2, pp. 432-446.

SANTOS, Boaventura de Sousa. (1998), Reinventar a Democracia. Lisboa, Gradiva.

SAWARD, Michael. (2009), "Authorisation and Authenticity: Representation and the Unelected". The Journal of Political Philosophy, vol. 17, no 1, pp. 1-22.

SCHARPF, Fritz W. (1970), Demokratietheorie zwischen Utopie und Anpassung. Konstanz, Universitätsverlag.

SCHMIDT, Manfred G. (1995), Demokratietheorien. Opladen, Leske \& Budrich.

SEELE, Andrew; PERUZZOTTI, Enrique. (2009), Participatory Innovation and Representative Democracy in Latin America. Baltimore, Johns Hopkins University Press Series.

SMITH, Graham. (2009), Democratic Innovations: Designing Institutions for Citizen Participation. Cambridge, Cambridge University Press.

SOUZA, Clóvis; PIRES, Roberto Rocha. (2013), “Conferências Nacionais como Interfaces Socioestatais: Seus Usos e Papéis na Perspectiva dos Gestores Federais", in L. Avritzer; C. H. L. Souza (orgs.), Conferências Nacionais: Atores, Dinâmicas Participativas e Efetividade. Brasília, Ipea. 
TATAGIBA, Luciana. (2005), “Conselhos Gestores de Políticas Públicas e Democracia Participativa: Aprofundando o Debate". Revista de Sociologia e Política, no 25, pp. 209-213.

URBINATI, Nadia. (2006), Representative Democracy: Principles and Genealogy. Chicago, Chicago University Press.

; WARREN, Mark. (2008), “The Concept of Representation in Contemporary Democratic Theory". Annual Review of Political Science, vol. 11, pp. 387-412.

WAMPLER, Brian. (2007), Participatory Budgeting in Brazil: Contestation, Cooperation, and Accountability. University Park, PA: Pennsylvania State University.

; TOUCHTON, Michael. (2013), “Improving Social Well-Being through New Democratic Institutions". Comparative Political Studies, vol. 47, no 10, pp. 1442-1469.

WARREN, Mark. (2002), “What Can Democratic Participation Mean Today?”. Political Theory, vol. 30, no 5, pp. 677-701. 


\section{RESUMO}

Mais Participação, Maior Responsividade? As Conferências Nacionais de Políticas Públicas e a Qualidade da Democracia no Brasil

Indagando se inovações democráticas podem, ao aumentar a participação da sociedade, ampliar a qualidade da democracia, o artigo toma uma das dimensões desta, a responsividade, como objeto de investigação. Propondo um modelo analítico deste conceito em três níveis (impacto nas políticas públicas, congruência temática e multidimensionalidade da participação), o artigo busca examinar se as Conferências Nacionais de Políticas Públicas aumentaram (ou não) a responsividade do Poder Legislativo brasileiro. Para isto, analisa-se a recepção das demandas das Conferências Nacionais pelo Poder Legislativo brasileiro entre 2003 e 2010, testando, por meio de análises descritivas e modelos de regressão logística, cada uma das três dimensões do conceito proposto.

Palavras-chave: participação; qualidade da democracia; inovações democráticas; responsividade; Conferências Nacionais de Políticas Públicas

\section{ABSTRACT \\ More Participation, Greater Responsiveness? National Public Policy Conferences and the Quality of Democracy in Brazil}

Using the dimension of responsiveness as its object of investigation, the following article aims to determine whether democratic innovations can enhance the quality of democracy by increasing society's participation. By proposing an analytical model for the concept across three levels (impact on public policies, thematic congruence, and the multi-dimensional nature of participation), the article seeks to examine whether National Public Policy Conferences increased responsiveness in the Brazilian Legislature. To do so, it analyzes the reception in the Brazilian Legislature of the demands made in the National Conferences from 2003 to 2010, using descriptive analyses and logistic regression models to evaluate each of the three dimensions of the concept proposed.

Key words: participation; quality of democracy; democratic innovations; responsiveness; National Public Policy Conferences 


\section{RÉSUMÉ}

Plus de Participation pour plus de Réceptivité ? Les Conférences

Nationales de Politiques Publiques et la Qualité de la Démocratie au Brésil

En se penchant sur la question de savoir si les innovations démocratiques, en augmentant la participation de la société, permettent d'améliorer la qualité de la démocratie, cet article prend comme objet spécifique d'étude l'une des dimensions de celle-ci, à savoir la réceptivité. À partir de la proposition d'un modèle analytique de ce concept à trois niveaux (impact sur les politiques publiques, congruence thématique et multi-dimensionnalité de la participation), cet article cherche à savoir si les Conférences nationales de politiques publiques ont augmenté (ou non) la réceptivité du Pouvoir législatif brésilien. Pour ce faire a été analysée la réception des demandes des Conférences nationales par le Pouvoir législatif brésilien entre 2003 et 2010, et testée, au moyen d'analyses descriptives et de modèles de régression logistique, chacune des trois dimensions du concept proposé.

Mots-clés: participation; qualité de la démocratie; innovations démocratiques; réceptivité; Conférences nationales de politiques publiques

\section{RESUMEN}

¿Más Participación, Mayor Acción Responsiva? Las Conferencias Nacionales de Políticas Públicas y la Calidad de la Democracia en Brasil

El artículo, en su valoración de si las innovaciones democráticas pueden ampliar la calidad de la democracia al aumentar la participación de la sociedad, toma una de las dimensiones democráticas, la capacidad responsiva, como objeto de investigación. Proponiendo un modelo analítico de este concepto en tres niveles (impacto en las políticas públicas, congruencia temática y multidimensionalidad de la participación), se busca examinar si las Conferencias Nacionales de Políticas Públicas aumentaron (o no) las acciones responsivas del poder legislativo brasileño. Para ello, se analiza la recepción de las demandas de las Conferencias Nacionales por parte del poder legislativo brasileño entre 2003 y 2010, y se examina, por medio de estudios descriptivos y modelos de regresión logística, cada una de las tres dimensiones del concepto propuesto.

Palabras clave: participación; calidad de la democracia; innovaciones democráticas; acción responsiva; Conferencias Nacionales de Políticas Públicas 